\title{
An Update on Type 2 Diabetes Mellitus as a Risk Factor for Dementia
}

\author{
Wei Li ${ }^{1}$, Edgar Huang ${ }^{2}$
}

\begin{abstract}
${ }^{1}$ Master of Physician Assistant Studies, School of Health and Rehabilitation Sciences, Indiana University Purdue University Indianapolis, Indianapolis, Indiana

${ }^{2}$ School of Informatics and Computing, Indiana University-Purdue

University Indianapolis, Indianapolis, Indiana
\end{abstract}

Running Title: T2DM and Dementia

Word count (abstract): 215

Keywords: Alzheimer's disease (AD), Mild Cognitive Impairment (MCI), Type 2

Diabetes Mellitus (T2DM), Vascular Dementia (VaD)

Correspondence:

Dr. Wei Li

Master of Physician Assistant Studies

School of Health \& Rehabilitation Sciences

Indiana University Purdue University Indianapolis

2039 N. Capitol Avenue, Indianapolis, IN 46202

Phone: $317-278-9575$

Fax: 317-278-9555

email:wl23@iu.edu 


\section{AUTHOR CONTRIBUTIONS}

Both authors contributed to content, draft and critical revisions of the manuscript. 


\begin{abstract}
With the rapidly expanding evidence on brain structural and functional changes in type 2 diabetes mellitus (T2DM) patients, there is an increasing need to update our understanding on how T2DM associates with dementia as well as the underlying pathophysiological mechanisms. A literature search of T2DM and dementia or cognition impairments was carried out in electronic databases Medline, EMBASE, and Google Scholar. In this review, the chosen evidence was limited to human subject studies only, and data on either type 1 diabetes mellitus (T1DM) or non-classified diabetes were excluded. T2DM is a risk factor for both vascular dementia $(\mathrm{VaD})$ and Alzheimer's disease (AD), although AD pathological marker studies have not provided sufficient evidence. T2DM interacts additively or synergistically with many factors including old age, hypertension, total cholesterol, and $A P O E \varepsilon 4$ carrier status for impaired cognition functions seen in patients with T2DM. In addition, comorbid T2DM can worsen the clinical presentations of patients with either AD or VaD. In summary, T2DM increases the risk for $A D$ through different mechanisms for $\mathrm{VaD}$ although some mechanisms may overlap. Tau-related neurofibrillary tangles instead of $\beta$ amyloid plaques are more likely to be the pathological biomarkers for T2DM-related dementia. Degeneration of neurons in the brain, impaired regional blood supply/metabolism, and genetic predisposition are all involved in T2DM-associated dementia or cognitive impairments.
\end{abstract}




\section{T2DM and Dementia: introduction}

Type 2 diabetes mellitus (T2DM) is one of the most common chronic metabolic diseases, which affects more than 300 million people worldwide [1]. With its defining characteristic of impaired glucose regulation, T2DM progresses clinically with slowly declining functions in multiple body organs and systems. Impaired cognitive functions are often seen in patients with T2DM. Dementia is a condition with impaired functions in language, memory, and execution functions. Based on etiology and clinical features, people with dementia can be classified into Alzheimer's disease (AD), vascular dementia $(\mathrm{VaD})$, frontotemporal dementia, Lewy body dementia and non-specific dementia. In this review, T2DM will be examined for its associations with the two most common types of dementia: $\mathrm{AD}$ and $\mathrm{VaD}$, which make more than $95 \%$ of all dementia cases. The underlying mechanisms of T2DM associated dementia will also be reviewed based on the expanding knowledge obtained from imaging and molecular pathological studies on brain structural and functional changes in patients with T2DM.

\section{T2DM as a Risk Factor for Dementia}

In 1996, a report from the Rotterdam study showed that T2DM was positively associated with dementia [2]. According to a 7-year follow-up study, patients with newly diagnosed T2DM had a $63 \%$ higher risk for developing dementia than those without T2DM [3]. From a retrospective study, hospital-admitted T2DM patients had a relative risk (RR) of 1.37 for dementia compared to controls [4]. By contrast, the RR for dementia diagnosis was 1.56 among newly onset T2DM patients compared to those participants without T2DM [5]. The increased risk for dementia in T2DM patients was 
associated with many factors (Table 1), including age [6, 7], apolipoprotein $E(A P O E)$ $\varepsilon 4$ carrier status [6], and medications, such as oral hypoglycemic agents and use of statins (lipid metabolism modifying agent) [6]. Other factors such as gender [7, 8], ethnicity [9], and body height [8] were also shown to be significantly associated with cognition changes in T2DM patients. Although APOE $\varepsilon 4$ carrier status did not attain significance by itself $[10,11]$, these T2DM patients carrying one or two APOE $\varepsilon 4$ allele had a significantly higher risk of dementia (both $A D$ and $V a D$ ) than those who were negative for T2DM or APOE \&4 allele [12]. In addition, the dementia risk for patients with T2DM and stroke is eight times more possible to increase relative to that for those without T2DM or stroke [13].

\section{Pathological Mechanisms Underlying the Impaired Cognition Functions}

Impaired cognition functions in patients with T2DM were manifested in a variety of domains, such as attention $[14,15,16]$, execution $[14,15,16,17,18]$, information

processing speed $[9,14,16,18,19,20]$, working memory $[14,15,17,18]$, and verbal memory [16, 20, 21, 22, 23]. Impaired cognition functions were associated with not only subcortical ischemic changes in the brain but also brain atrophy [14]. The atrophic brain changes associated with T2DM will be discussed in details in a separate section next. Worse execution function and memory are correlated predominantly with less gray matter density and reduced glucose metabolism in fronto-temporal areas [24]. The impaired execution function was also shown to be associated with the widespread white matter abnormalities [15]. T2DM patients performed significantly worse in language $[25,26]$ and visuospatial abilities $[15,19,21,25,26]$ than those without 
T2DM. In one study with a relatively small sample size, T2DM was found to be associated with a lower level of semantic memory in older adults than in those without T2DM, but not with episodic memory, working memory, visuospatial ability or global cognition [27]. Verbal memory impairment was associated with compromised microstructural integrity of the left parahippocampal gyrus [23].

The status of T2DM patients is usually described with its duration and overall glycemic control. Long duration of T2DM was associated with a poor cognitive function [28] especially on attention, working memory, and execution function [29]. For patients with T2DM, cognitive function was shown to be negatively associated with $\mathrm{HbA1c}$ [21]. The inverse relationship between $\mathrm{HbA} 1 \mathrm{c}$ and cognitive performance was even seen in nondiabetic subjects [30]. Therefore, hyperglycemia is associated with both impaired cognition functions and atrophic changes of the brain. High plasma glucose levels within the normal range $(<6.1 \mathrm{mmol} / \mathrm{L})$ were associated with atrophy in the hippocampus and amygdala [31]. On the other hand, T2DM patients with normoglycemia lost less whole-brain volume and exhibited a lower rate of converting mild cognitive impairment $(\mathrm{MCl})$ to $A D$ than those with hyperglycemia [32]. Both advanced glycation end products (AGEs) and glycoxidations were elevated in patients with T2DM compared to controls [33, 34, 35], which are important for the pathogenesis of T2DM and diabetic compliations. In addition, serum levels of AGEs, and C-reactive protein (CRP) were significantly increased in elderly patients with both $\mathrm{MCl}$ and T2DM compared to those with T2DM only [36]. In AD patients, AGEs were found to be elevated in the central nervous system [37] and were present mainly with intracellular neurofibrillary tangles (NFTs) [38]. The evidence suggested glycation, oxidative stress 
as well as inflammation were involved in the impaired cognition functions in patients with T2DM (Table 2). Although insulin treatment was shown to increase the odds ratio of dementia in T2DM patients $[2,7,39]$, it might simply indicate a more severe status of diabetes.

T2DM patients with stable HbA1c levels over time had better cognition functions than those with fluctuating $\mathrm{HbA} 1 \mathrm{c}$ levels [40]. Therefore, a fluctuating glucose level was suggested to be involved in the cognition decline in T2DM patients as impaired cognitions were seen among T2DM patients with hypoglycemic episodes as well [41, 42] (Figure 1). For instance, the risk of dementia in T2DM patients was positively correlated with the number of hypoglycemic episodes [41]. The RR was 1.6 for dementia in T2DM patients who had hypoglycemic episodes compared to those who did not have hypoglycemia after controlling for age and gender [7]. Moreover, severe hypoglycemia was associated with poor cognition functions and an accelerated cognitive decline in T2DM patients [42].

Other factors such as hypertension and vascular changes may also contribute to the cognition impairments seen in T2DM patients (Figure 1). Dementia was significantly and independently associated with hypertension in T2DM patients [43]. The cognitive impairment prevalence was found to be significantly higher in people with both T2DM and hypertension than in those normotensive T2DM patients [44]. Small vessel disease not only could predict future cognitive decline in elderly people with T2DM [45] but also was associated with the hippocampal atrophic changes [46] (Figure 1). Further, accelerated cognitive decline in patients with T2DM was associated with vascular damages [47]; arterial stiffness was increased and significantly associated with 
cognition impairments in T2DM patients [16].

T2DM was also shown as a risk factor for $\operatorname{VaD}[48,49,50]$ and it affected $\operatorname{VaD}$ more than AD [2] (Figure 1). The high overlap rate between dementia and ischemic stroke suggested that vascular events play an important role in the pathogenesis of T2DMassociated dementia [3]. Lastly, patients with both T2DM and VaD showed a significantly earlier onset of $\mathrm{VaD}$, a faster rate of cognitive decline, and a greater prevalence of neuropsychiatric symptoms than patients with VaD only [50] -these findings suggesting that T2DM had either additive or synergistic effects with VaD to worsen the clinical presentations.

T2DM patients with severe diabetic retinal disease have a $42 \%$ increased risk of incident dementia [51]. On the contrary, one report showed that the severity of diabetic retinopathy was demonstrated to be inversely associated with the cognition impairments in T2DM patients [52]. In addition, the presence and number of microinfarcts or microbleeds were unrelated to cognitive performance in patients with T2DM [53]. Therefore, unlike other factors, the role of micorvascular changes is inconclusive for T2DM associated cognitive impairments.

\section{T2DM and Atrophic Brain Changes}

Atrophic brain changes in T2DM patients were manifested in volume changes either for the whole brain or for regional brain areas (Table 1). Whole brain atrophy was observed in many studies $[19,47,54,55,56]$ except one [57] for patients with T2DM. The cerebral atrophy in T2DM patients was associated with an increased lateral ventricle volume $[56,58]$. In addition, patients with $A D$ and T2DM had more severe 
cortical atrophy compared with the AD only group [59]. As sensitive early markers of AD-type neuropathology, hippocampal and amygdalar atrophy seen in T2DM were independent of vascular pathology $[59,60]$. The atrophic hippocampus was reported in some studies [19, 22, 41, 54, 55], but T2DM-related brain volume reductions were reported to be restricted to the hippocampus in other studies [23, 61]. In one report, patients with T2DM had a greater whole brain atrophy but not hippocampal atrophy in comparison to controls [62]. T2DM was also reported to be associated with a lower bilateral frontal and parietal cortical thickness than in those without T2DM [63].

The association between T2DM and gray matter (GM) or white matter (WM) was also reported by many studies. For example, T2DM was associated with a smaller GM volume [58]. T2DM patients showed extensively decreased GM volume compared to healthy controls in certain brain regions, including the superior and middle temporal gyrus, the superior and medial frontal gyrus and the middle occipital gyrus [64]. T2DMrelated GM loss was seen mainly in medial temporal, anterior cingulate, and medial frontal lobes, whereas WM loss was distributed in frontal and temporal regions [19]. To summarize, T2DM was associated with atrophic brain changes, and variations in atrophic brain regions might reflect the interaction of many factors including T2DM duration, genetic predisposition, age, gender, and age at onset of T2DM [65].

\section{T2DM and $\mathrm{MCl}$}

$\mathrm{MCl}$ is generally considered to be a transitional phase between normal cognition and dementia. The $\mathrm{MCl}$ manifests as a stage of cognitive dysfunction with a mini mental status examination (MMSE) score falling between 23 and 27 out a toal of 30 points. On 
average, the presence of T2DM at baseline shortened the duration of conversion from normal cognition to $\mathrm{MCl}$ by seven years [66]. Further, T2DM was associated with a higher $\mathrm{MCl}$ prevalence than in the general population $[67,68]$. Patients with both T2DM and $\mathrm{MCl}$ had a faster cognitive deterioration process than patients with $\mathrm{MCl}$ only [32]; this finding suggested an interaction between T2DM and $\mathrm{MCl}$. However, the association between T2DM and non-amnestic $\mathrm{MCl}$ was attenuated after socioeconomic and vascular risk factors were controlled [68].

Age [69, 70], blood pressure [69], body mass index (BMI) [71], gender [72], current smoking status $[27,67,71]$, duration of diabetes $[67,71,73]$, fasting blood glucose (FBG) [67], HbA1c [67, 71], high-density lipoprotein cholesterol [71], immunoreactive insulin [67], total cholesterol [71], and triglycerides [71] were involved in developing $\mathrm{MCl}$ in T2DM patients. Age, education, and systolic blood pressure were significantly associated with an increased risk of $\mathrm{MCl}$ in older patients with T2DM [69]. High blood pressure [73] and older age [70] were risk factors for cognition impairments while education had a protective role against dementia [70]. Older age ( $>75$ years) and long duration of diabetes are major risk factors for converting $\mathrm{MCl}$ to dementia, while the use of oral hypoglycemic agents or statins was associated with a significantly reduced risk for converting $\mathrm{MCl}$ to dementia [74]. T2DM has been found to be associated with $\mathrm{MCl}$ or $\mathrm{MCl}$ subtypes in middle-aged (50-65 years old) subjects but not in elderly individuals (66-80 years old) [72]. However, T2DM was shown to be associated with an increased risk of $\mathrm{MCl}$ in an elderly group of subjects (70 years and older) in another study [75]. High BMI, high 2-hour postprandial glucose, and poor glycemic control were significant independent predictors of cognition impairments in patients with both T2DM 
and $\mathrm{MCl}$ [76]. T2DM patients with $\mathrm{MCl}$ had a longer duration of diabetes [77, 78, 79], fewer years of education [77], higher $\mathrm{HbA} 1 \mathrm{c}[78,79]$, higher low density lipoprotein (LDL) cholesterol [78], higher triglyceride [78] and higher fasting blood glucose (FBG) [77] than T2DM patients without cognitive impairment. Cognition functions were inversely correlated with T2DM duration [77], FBG [77], history of hypertension [77], non-high-density lipoprotein cholesterol [71], and total cholesterol [78]. Insulin treatment was associated with a lower level of cognitive performance level in T2DM patients with $\mathrm{MCl}$ than in patients with T2DM only [79], however, the insulin treatment might simply indicate a more severe status of diabetes, as stated earlier.

T2DM may worsen the clinical presentation of patients with $\mathrm{MCl}$ by impairing psychomotor functions [80]. In addition, patients with both $\mathrm{MCl}$ and T2DM had a worse outcome in attention, information processing speed, and memory than non-diabetic $\mathrm{MCl}$ patients [81]. T2DM patients with $\mathrm{MCl}$ were shown to have a lower volume of the left middle temporal gyrus (MTG) than patients with T2DM only [64]. The atrophic changes in MTG were correlated positively with the cognitive performance score of Montreal Cognitive Assessment (MoCA) [64]. Therefore, structural changes can be observed in certain brain areas in the patients with T2DM who showed an early stage of cognitive impairment.

\section{T2DM as a Risk Factor for AD}

As the most common type of dementia, $A D$ progresses clinically with impaired cognition functions, including memory. T2DM was shown to be associated with an increased risk of $A D$ [82]. In 1999, the Rotterdam study reported that T2DM could double the risk of 
$A D$ [39]. More recently, T2DM was shown to be associated with a $60 \%$ increase of $A D$ risk [83]. The association between T2DM and AD was not observed in one study with very old T2DM subjects ( $\geq 80$ years old) (48). The association between T2DM and AD was probably specific with the age at onset of T2DM as the same relationship was observed between the age at onset of T2DM and $\mathrm{MCl}$ (72). Although the cortical atrophy in T2DM was reported to resemble the pattern as in preclinical AD [19], the presence of T2DM does not affect amyloid and neurofibrillary tangle burden in a sample of clinically and pathologically confirmed AD cases [84]. In addition, diffuse and neuritic plaques were not more common in T2DM than in control subjects [85]. The 11C Pittsburgh compound B (11C-PiB) (an amyloid plaque marker) retention ratio was similar in diabetic individuals versus non-diabetic individuals [86]. This finding suggested that the amyloid load was not significantly influenced by T2DM status. Moreover, the cognition impairments in T2DM were not associated with the AD-type pathology [87]. On the contrary, the T2DM was shown to be negatively associated with $A D$ but positively associated with $\mathrm{VaD}$ [88]. For example, fewer neuritic plaques and NFTs in the cerebral cortex and hippocampus have been shown in diabetics than in the non-diabetics [89]. Hypometabolism in AD signature regions was two times more likely to be seen in diabetics than in nondiabetics [86]. It is likely that abnormalities in glucose metabolism interact with genetic predisposition leading to cognition decline in patients with T2DM (Figure 1). For instance, T2DM and APOE $\varepsilon 4$ allele synergistically increased the number of pathological changes, such as neuritic plaques in hippocampus, NFTs in the cortex and hippocampus, and amyloid angiopathy in the brain [49]. Therefore, T2DM may accelerate the already existing cognitive impairments, 
and the deteriorating effects of T2DM are more prominent in people with certain genetic predispositions (Figure 1). For example, individuals with both T2DM and APOE $\varepsilon 4$ allele had a risk ratio (RR) of 5.5 for $A D$ compared with those with neither of them [49]. Lastly, a higher prevalence of T2DM or impaired glucose metabolism in patients with AD than in control subjects supported the involvement of impaired glucose metabolism in AD development [85]. On one hand, T2DM could worsen already impaired cognition functions through additive or synergistic effects with AD [90]. On the other hand, insulin therapy was shown to be effective in slowing cognitive decline in patients with both $A D$ and T2DM [91].

Other factors are associated with an increased AD risk in T2DM patients. For instance, the use of statins might decrease the risk of AD in patients with T2DM while no benefit was observed in non-AD type dementia [92]. A low insulin response at baseline was associated with a higher cumulative risk of $A D$, and the association was stronger in subjects without the APOE $\varepsilon 4$ allele [93]. Insulin resistance might be a signal of AD risk, which was associated with reduced cerebral glucose metabolism and subtle cognitive impairments at the early stage of T2DM, even before the onset of $\mathrm{MCl}$ [94]. Increasing insulin resistance was associated with more amygdalar atrophy in T2DM patients [60]. Patients with insulin resistance had increased the levels of $A \beta$ and inflammatory agents in brain [95]. All these pathological changes could be responsible for the impaired cognition functions seen in T2DM patients (Figure 1 and Table 2).

At molecular and cellular level, the deficiency of insulin-PI3K-AKT signaling was more severe in individuals with both T2DM and AD than in those with either one alone [96]. The level of PI3K-AKT signaling was negatively correlated with tau phosphorylation 
[96]. In addition, both neuronal membrane glucose transporter 3 and GlcNAcylation levels of tau were decreased in the brain of T2DM patients due to an increased tau phosphorylation [97]. In T2DM patients, an increased level of phosphorylated tau might cause neurons to degenerate by causing NFTs to accumulate in these cells.

\section{T2DM and AD Biomarker Levels}

Amyloid- $\beta(A \beta)$ plaques and NFTs are pathological biomarkers for $A D$, while T2DM is characterized by the deposition of islet amyloid polypeptide (IAPP, also known as amylin) within beta cells of the pancreatic islets. All these biomarkers (A $\beta$ plaques, NFTs and amylin) are in the form of mis-folded proteins. $A \beta$ autoantibody levels increased $45 \%$ in patients with T2DM compared with age-matched controls [98]. However, T2DM was associated neither with ${ }^{11} \mathrm{C}$ - Pittsburgh compound B standardized uptake value ratio in any brain region for measuring $A \beta$ plaques nor with cerebrospinal fluid (CSF) A 42 levels [63]. By contrast, T2DM was associated significantly with increased levels of CSF total tau and phosphorylated tau (pTau) [63]. Tau is a microtubule-associated protein, and the pTau level is closely related to the formation of NFTs. T2DM patients have a higher pTau level measured from frontal cortices than the control subjects [97]. So Tau and pTau instead of $\beta$ amyloid plaques is more likely to be the sensitive pathological biomarker for T2DM- related dementia. However, studying biomarker changes longitudinally and/or pathological changes from autopsies is needed for disclosing relationship between T2DM and dementia. 


\section{References}

1. Rivillas-Acevedo L, Sánchez-López C, Amero C, Quintanar L (2015) Structural basis for the inhibition of truncated islet amyloid polypeptide aggregation by $\mathrm{Cu}(\mathrm{II})$ : insights into the bioinorganic chemistry of type II diabetes. Inorg Chem 54, 3788-3796.

2. Ott A, Stolk RP, Hofman A, van Harskamp F, Grobbee DE, Breteler MM (1996) Association of diabetes mellitus and dementia: the Rotterdam Study. Diabetologia 39, $1392-1397$.

3. Cheng PY, Sy HN, Wu SL, Wang WF, Chen YY (2012) Newly diagnosed type 2 diabetes and risk of dementia: a population-based 7-year follow-up study in Taiwan. $\mathrm{J}$ Diabetes Complications 26, 382-387.

4. Smolina K, Wotton CJ, Goldacre MJ (2015) Risk of dementia in patients hospitalised with type 1 and type 2 diabetes in England, 1998-2011: a retrospective national record linkage cohort study. Diabetologia 58, 942-950.

5. Cheng C, Lin CH, Tsai YW, Tsai CJ, Chou PH, Lan TH (2014) Type 2 diabetes and antidiabetic medications in relation to dementia diagnosis. J Gerontol A Biol Sci Med Sci 69, 1299-1305.

6. Fei M, Yan Ping Z, Ru Juan M, Ning Ning L, Lin G (2013) Risk factors for dementia with type 2 diabetes mellitus among elderly people in China. Age Ageing 42, 398-400. 7. Lin CH, Sheu WH (2013) Hypoglycaemic episodes and risk of dementia in diabetes mellitus: 7-year follow-up study. J Intern Med 273, 102-110.

8. West RK, Ravona-Springer R, Heymann A, Schmeidler J, Leroith D, Koifman K, Guerrero-Berroa E, Preiss R, Hoffman H, Silverman JM, Beeri MS (2015) Shorter adult height is associated with poorer cognitive performance in elderly men with type II 
diabetes. J Alzheimers Dis 44, 927-935.

9. Mayeda ER, Haan MN, Neuhaus J, Yaffe K, Knopman DS, Sharrett AR, Griswold ME, Mosley TH (2014) Type 2 diabetes and cognitive decline over 14 years in middleaged African Americans and whites: the ARIC Brain MRI Study. Neuroepidemiology 43, 220-227.

10. Percy M, Somerville MJ, Hicks M, Garcia A, Colelli T, Wright E, Kitaygorodsky J, Jiang A, Ho V, Parpia A, Wong MK (2014) Risk factors for development of dementia in a unique six-year cohort study. I. An exploratory, pilot study of involvement of the E4 allele of apolipoprotein E, mutations of the hemochromatosis-HFE gene, type 2 diabetes, and stroke. J Alzheimers Dis 38, 907-922.

11. van Eersel ME, Joosten H, Gansevoort RT, Dullaart RP, Slaets JP, Izaks GJ (2013) The interaction of age and type 2 diabetes on executive function and memory in persons aged 35 years or older. PLoS One 8, e82991.

12. Irie F, Fitzpatrick AL, Lopez OL, Kuller LH, Peila R, Newman AB, Launer LJ (2008) Enhanced risk for Alzheimer disease in persons with type 2 diabetes and APOE epsilon4: the Cardiovascular Health Study Cognition Study. Arch Neurol 65, 89-93. 13. Haan MN, Mungas DM, Gonzalez HM, Ortiz TA, Acharya A, Jagust WJ (2003) Prevalence of dementia in older latinos: the influence of type 2 diabetes mellitus, stroke and genetic factors. J Am Geriatr Soc 51, 169-177.

14. Manschot SM, Brands AM, van der Grond J, Kessels RP, Algra A, Kappelle LJ, Biessels GJ (2006) Brain magnetic resonance imaging correlates of impaired cognition in patients with type 2 diabetes. Diabetes 55, 1106-1113.

15. Zhang J, Wang Y, Wang J, Zhou X, Shu N, Wang Y, Zhang Z (2014) White matter 
integrity disruptions associated with cognitive impairments in type 2 diabetic patients. Diabetes 63, 3596-3605.

16. Mehrabian S, Raycheva M, Gateva A, Todorova G, Angelova P, Traykova M, Stankova T, Kamenov Z, Traykov L (2012) Cognitive dysfunction profile and arterial stiffness in type 2 diabetes. J Neurol Sci 322, 152-156.

17. Chen Y, Liu Z, Zhang J, Xu K, Zhang S, Wei D, Zhang Z (2014) Altered brain activation patterns under different working memory loads in patients with type 2 diabetes. Diabetes Care 37, 3157-3163.

18. Szémán B, Nagy G, Varga T, Veres-Székely A, Sasvári M, Fitala D, Szollosi A, Katonai R, Kotyuk E, Somogyi A (2012) Changes in cognitive function in patients with diabetes mellitus. Orv Hetil 153, 323-329.

19. Moran C, Phan TG, Chen J, Blizzard L, Beare R, Venn A, Münch G, Wood AG, Forbes J, Greenaway TM, Pearson S, Srikanth V (2013) Brain atrophy in type 2 diabetes: regional distribution and influence on cognition. Diabetes Care 36, 40364042.

20. Hugenschmidt CE, Hsu FC, Hayasaka S, Carr JJ, Freedman BI, Nyenhuis DL, Williamson JD, Bowden DW (2013) The influence of subclinical cardiovascular disease and related risk factors on cognition in type 2 diabetes mellitus: The DHS-Mind study. $J$ Diabetes Complications 27, 422-428.

21. Zhou H, Lu W, Shi Y, Bai F, Chang J, Yuan Y, Teng G, Zhang Z (2010) Impairments in cognition and resting-state connectivity of the hippocampus in elderly subjects with type 2 diabetes. Neurosci Lett 473, 5-10.

22. Bruehl H, Wolf OT, Sweat V, Tirsi A, Richardson S, Convit A (2009) Modifiers of 
cognitive function and brain structure in middle-aged and elderly individuals with type 2 diabetes mellitus. Brain Res 1280,186-194.

23. Yau PL, Kluger A, Borod JC, Convit A (2014) Neural substrates of verbal memory impairments in adults with type 2 diabetes mellitus. J Clin Exp Neuropsychol 36, 74-87. 24. García-Casares N, Jorge RE, García-Arnés JA, Acion L, Berthier ML, GonzalezAlegre P, Nabrozidis A, Gutiérrez A, Ariza MJ, Rioja J, González-Santos P (2014) Cognitive dysfunctions in middle-aged type 2 diabetic patients and neuroimaging correlations: a cross-sectional study. J Alzheimers Dis 42,1337-1346.

25. Bangen KJ, Gu Y, Gross AL, Schneider BC, Skinner JC, Benitez A, Sachs BC, Shih R, Sisco S, Schupf N, Mayeux R, Manly JJ, Luchsinger JA (2015) Relationship Between Type 2 Diabetes Mellitus and Cognitive Change in a Multiethnic Elderly Cohort. J Am Geriatr Soc 63, 1075-1083.

26. Cooray G, Nilsson E, Wahlin A, Laukka EJ, Brismar K, Brismar T (2011) Effects of intensified metabolic control on CNS function in type 2 diabetes.

Psychoneuroendocrinology 36, 77-86.

27. Arvanitakis Z, Wilson RS, Li Y, Aggarwal NT, Bennett DA (2006) Diabetes and function in different cognitive systems in older individuals without dementia. Diabetes Care 29, 560-565.

28. Beeri MS, Ravona-Springer R, Moshier E, Schmeidler J, Godbold J, Karpati T, Leroith D, Koifman K, Kravitz E, Price R, Hoffman H, Silverman JM, Heymann A (2014) The Israel Diabetes and Cognitive Decline (IDCD) study: Design and baseline characteristics. Alzheimers Dement 10, 769-778.

29. Yogi-Morren D, Galioto R, Strandjord SE, Kennedy L, Manroa P, Kirwan JP, 
Kashyap S, Gunstad J (2014) Duration of type 2 diabetes and very low density lipoprotein levels are associated with cognitive dysfunction in metabolic syndrome. Cardiovasc Psychiatry Neurol 2014, 656341.

30. U'Ren RC, Riddle MC, Lezak MD, Bennington-Davis M (1990) The mental efficiency of the elderly person with type II diabetes mellitus. J Am Geriatr Soc 38, 505510.

31. Cherbuin N, Sachdev P, Anstey KJ (2012) Higher normal fasting plasma glucose is associated with hippocampal atrophy: The PATH Study. Neurology 79, 1019-1026. 32. Morris JK, Vidoni ED, Honea RA, Burns JM (2014) Impaired glycemia increases disease progression in mild cognitive impairment. Neurobiol Aging 35, 585-589. 33. Kalousová M, Skrha J, Zima T (2002) Advanced glycation end-products and advanced oxidation protein products in patients with diabetes mellitus. Physiol Res 51, 597-604.

34. Krapfenbauer K, Birnbacher R, Vierhapper H, Herkner K, Kampel D, Lubec G (1998) Glycoxidation, and protein and DNA oxidation in patients with diabetes mellitus. Clin Sci (Lond) 95, 331-337.

35. Nowotny K, Jung T, Höhn A, Weber D, Grune T (2015) Advanced glycation end products and oxidative stress in type 2 diabetes mellitus. Biomolecules $5,194-222$. 36. Gorska-Ciebiada M, Saryusz-Wolska M, Borkowska A, Ciebiada M, Loba J. C-Reactive Protein, Advanced Glycation End Products, and Their Receptor in Type 2 Diabetic, Elderly Patients with Mild Cognitive Impairment (2015) Front Aging Neurosci 7, 209.

37. Thome J, Münch G, Müller R, Schinzel R, Kornhuber J, Blum-Degen D, Sitzmann 
L, Rösler M, Heidland A, Riederer P (1996) Advanced glycation endproductsassociated parameters in the peripheral blood of patients with Alzheimer's disease. Life Sci 59, 679-685.

38. Sasaki N, Fukatsu R, Tsuzuki K, Hayashi Y, Yoshida T, Fujii N, Koike T, Wakayama I, Yanagihara R, Garruto R, Amano N, Makita Z (1998) Advanced glycation end products in Alzheimer's disease and other neurodegenerative diseases. Am J Pathol 153, 1149-1155.

39. Ott A, Stolk RP, van Harskamp F, Pols HA, Hofman A, Breteler MM (1999) Diabetes mellitus and the risk of dementia: The Rotterdam Study. Neurology 53, 19371942.

40. Ravona-Springer R, Heymann A, Schmeidler J, Moshier E, Godbold J, Sano M, Leroith D, Johnson S, Preiss R, Koifman K, Hoffman H, Silverman JM, Beeri MS (2014) Trajectories in glycemic control over time are associated with cognitive performance in elderly subjects with type 2 diabetes. PLoS One 9, e97384.

41. Whitmer RA, Karter AJ, Yaffe K, Quesenberry CP Jr, Selby JV (2009) Hypoglycemic episodes and risk of dementia in older patients with type 2 diabetes mellitus. JAMA 301, 1565-1572.

42. Feinkohl I, Aung PP, Keller M, Robertson CM, Morling JR, McLachlan S, Deary IJ, Frier BM, Strachan MW, Price JF (2014) Severe hypoglycemia and cognitive decline in older people with type 2 diabetes: the Edinburgh type 2 diabetes study. Diabetes Care $37,507-515$.

43. Bruce DG, Harrington N, Davis WA, Davis TM (2001) Dementia and its associations in type 2 diabetes mellitus: the Fremantle Diabetes Study. Diabetes Res 
Clin Pract 53, 165-172.

44. Petrova M, Prokopenko S, Pronina E, Mozheyko E (2010) Diabetes type 2, hypertension and cognitive dysfunction in middle age women. J Neurol Sci 299, 39-41. 45. Imamine R, Kawamura T, Umemura T, Umegaki H, Kawano N, Hotta M, Kouchi $\mathrm{Y}$, Hatsuda S, Watarai A, Kanai A, Nakashima E, Sano T, Sakakibara T, Nakamura J, Hotta N (2011) Does cerebral small vessel disease predict future decline of cognitive function in elderly people with type 2 diabetes? Diabetes Res Clin Pract 94, 91-99. 46. Brundel M, van den Heuvel M, de Bresser J, Kappelle LJ, Biessels GJ (2010) Cerebral cortical thickness in patients with type 2 diabetes. J Neurol Sci 299, 126-130. 47. Reijmer YD, van den Berg E, de Bresser J, Kessels RP, Kappelle LJ, Algra A, Biessels GJ (2011) Accelerated cognitive decline in patients with type 2 diabetes: MRI correlates and risk factors. Diabetes Metab Res Rev 27, 195-202.

48. Hassing LB, Johansson B, Nilsson SE, Berg S, Pedersen NL, Gatz M, McClearn G (2002) Diabetes mellitus is a risk factor for vascular dementia, but not for Alzheimer's disease: a population-based study of the oldest old. Int Psychogeriatr 14, 239-248. 49. Peila R, Rodriguez BL, Launer LJ (2002) Type 2 diabetes, APOE gene, and the risk for dementia and related pathologies: The Honolulu-Asia Aging Study. Diabetes 51, $1256-1262$.

50. Murthy SB, Jawaid A, Qureshi SU, Kalkonde Y, Wilson AM, Johnson ML, Kunik ME, Schulz PE (2010) Does diabetes mellitus alter the onset and clinical course of vascular dementia? Behav Neurol 23, 145-151.

51. Exalto LG, Biessels GJ, Karter AJ, Huang ES, Quesenberry CP Jr, Whitmer RA (2014) Severe diabetic retinal disease and dementia risk in type 2 diabetes. $J$ 
Alzheimers Dis 42 Suppl 3, S109-117.

52. Crosby-Nwaobi RR, Sivaprasad S, Amiel S, Forbes A (2013) The relationship between diabetic retinopathy and cognitive impairment. Diabetes Care 36, 3177-3186. 53. Brundel M, Reijmer YD, van Veluw SJ, Kuijf HJ, Luijten PR, Kappelle LJ, Biessels GJ (2014) Cerebral microvascular lesions on high-resolution 7-Tesla MRI in patients with type 2 diabetes. Diabetes 63, 3523-3529.

54. Kamiyama K, Wada A, Sugihara M, Kurioka S, Hayashi K, Hayashi T, Yoshisako T, Yamamoto N, Tsuchie Y, Yamaguchi S, Sugimoto T, Kitagaki H (2010) Potential hippocampal region atrophy in diabetes mellitus type 2: a voxel-based morphometry VSRAD study. Jpn J Radiol 28, 266-272.

55. Hayashi K, Kurioka S, Yamaguchi T, Morita M, Kanazawa I, Takase H, Wada A, Kitagaki H, Nagai A, Bokura H, Yamaguchi S, Sugimoto T (2011) Association of cognitive dysfunction with hippocampal atrophy in elderly Japanese people with type 2 diabetes. Diabetes Res Clin Pract 94, 180-185.

56. de Bresser J, Tiehuis AM, van den Berg E, Reijmer YD, Jongen C, Kappelle LJ, Mali WP, Viergever MA, Biessels GJ (2010) Progression of cerebral atrophy and white matter hyperintensities in patients with type 2 diabetes. Diabetes Care 33, 1309-1314. 57. Wang C, Fu K, Liu H, Xing F, Zhang S (2014) Brain structural changes and their correlation with vascular disease in type 2 diabetes mellitus patients: a voxel-based morphometric study. Neural Regen Res 9, 1548-1556.

58. Jongen C, van der Grond J, Kappelle LJ, Biessels GJ, Viergever MA, Pluim JP (2007) Automated measurement of brain and white matter lesion volume in type 2 diabetes mellitus. Diabetologia 50,1509-1516. 
59. Biessels GJ, De Leeuw FE, Lindeboom J, Barkhof F, Scheltens P (2006) Increased cortical atrophy in patients with Alzheimer's disease and type 2 diabetes mellitus. $J$ Neurol Neurosurg Psychiatry 77, 304-307.

60. den Heijer T, Vermeer SE, van Dijk EJ, Prins ND, Koudstaal PJ, Hofman A, Breteler MM (2003) Type 2 diabetes and atrophy of medial temporal lobe structures on brain MRI. Diabetologia 46, 1604-1610.

61. Gold SM, Dziobek I, Sweat V, Tirsi A, Rogers K, Bruehl H, Tsui W, Richardson S, Javier fE, Convit A (2007) Hippocampal damage and memory impairments as possible early brain complications of type 2 diabetes. Diabetologia $\mathbf{5 0 , 7 1 1 - 7 1 9 . ~}$

62. Wisse LE, de Bresser J, Geerlings MI, Reijmer YD, Portegies ML, Brundel M, Kappelle LJ, van der Graaf Y, Biessels GJ (2014) Global brain atrophy but not hippocampal atrophy is related to type 2 diabetes. J Neurol Sci 344, 32-36.

63. Moran C, Beare R, Phan TG, Bruce DG, Callisaya ML, Srikanth V (2015) Type 2 diabetes mellitus and biomarkers of neurodegeneration. Neurology 85, 1123-1130. 64. Zhang Y, Zhang X, Zhang J, Liu C, Yuan Q, Yin X, Wei L, Cui J, Tao R, Wei P, Wang J (2014) Gray matter volume abnormalities in type 2 diabetes mellitus with and without mild cognitive impairment. Neurosci Lett 562, 1-6.

65. Roberts RO, Knopman DS, Przybelski SA, Mielke MM, Kantarci K, Preboske GM, Senjem ML, Pankratz VS, Geda YE, Boeve BF, Ivnik RJ, Rocca WA, Petersen RC, Jack CR Jr (2014) Association of type 2 diabetes with brain atrophy and cognitive impairment. Neurology 82, 1132-1141.

66. Kryscio RJ, Abner EL, Lin Y, Cooper GE, Fardo DW, Jicha GA, Nelson PT, Smith CD, Van Eldik LJ, Wan L, Schmitt FA (2013) Adjusting for mortality when identifying 
risk factors for transitions to mild cognitive impairment and dementia. J Alzheimers Dis 35, 823-832.

67. Gao Y, Xiao Y, Miao R, Zhao J, Cui M, Huang G, Fei M (2016) The prevalence of mild cognitive impairment with type 2 diabetes mellitus among elderly people in China: A cross-sectional study. Arch Gerontol Geriatr 62, 138-142.

68. Luchsinger JA, Reitz C, Patel B, Tang MX, Manly JJ, Mayeux R (2007) Relation of diabetes to mild cognitive impairment. Arch Neurol 64, 570-575.

69. Lee YJ, Kang HM, Kim NK, Yang JY, Noh JH, Ko KS, Rhee BD, Kim DJ (2014) Factors associated for mild cognitive impairment in older korean adults with type 2 diabetes mellitus. Diabetes Metab J 38,150-157.

70. Solfrizzi V, Panza F, Colacicco AM, D'Introno A, Capurso C, Torres F, Grigoletto F, Maggi S, Del Parigi A, Reiman EM, Caselli RJ, Scafato E, Farchi G, Capurso A (2004) Vascular risk factors, incidence of $\mathrm{MCl}$, and rates of progression to dementia. Neurology 63, 1882-1891.

71. Niu MJ, Yin FZ, Liu LX, Fang Y, Xuan XM, Wu GF (2013) Non-high-density lipoprotein cholesterol and other risk factors of mild cognitive impairment among Chinese type 2 diabetic patients. J Diabetes Complications 27, 443-446.

72. Winkler A, Dlugaj M, Weimar C, Jöckel KH, Erbel R, Dragano N, Moebus S (2014) Association of diabetes mellitus and mild cognitive impairment in middle-aged men and women. J Alzheimers Dis 42, 1269-1277.

73. Chen RH, Jiang XZ, Zhao XH, Qin YL, Gu Z, Gu PL, Zhou B, Zhu ZH, Xu LY, Zou YF (2012) Risk factors of mild cognitive impairment in middle aged patients with type 2 diabetes: a cross-section study. Ann Endocrinol (Paris) 73, 208-212. 
74. Ma F, Wu T, Miao R, Xiao YY, Zhang W, Huang G (2015) Conversion of mild cognitive impairment to dementia among subjects with diabetes: a population-based study of incidence and risk factors with five years of follow-up. J Alzheimers Dis 43,1441-1449.

75. Roberts RO, Knopman DS, Geda YE, Cha RH, Pankratz VS, Baertlein L, Boeve BF, Tangalos EG, Ivnik RJ, Mielke MM, Petersen RC (2014) Association of diabetes with amnestic and nonamnestic mild cognitive impairment. Alzheimers Dement 10, 1826.

76. Rizzo MR, Barbieri M, Boccardi V, Angellotti E, Marfella R, Paolisso G (2014) Dipeptidyl peptidase-4 inhibitors have protective effect on cognitive impairment in aged diabetic patients with mild cognitive impairment. J Gerontol A Biol Sci Med Sci 69, $1122-1131$.

77. Chen RH, Zhao XH, Gu Z, Gu PL, Zhou B, Zhu ZH, Xu LY, Zou YF, Jiang XZ (2014) Serum levels of 25-hydroxyvitamin D are associated with cognitive impairment in type 2 diabetic adults. Endocrine 45, 319-324.

78. Chen G, Cai L, Chen B, Liang J, Lin F, Li L, Lin L, Yao J, Wen J, Huang H (2011) Serum level of endogenous secretory receptor for advanced glycation end products and other factors in type 2 diabetic patients with mild cognitive impairment. Diabetes Care 34, 2586-2590.

79. Gao Y, Xiao Y, Miao R, Zhao J, Zhang W, Huang G, Ma F (2015) The characteristic of cognitive function in Type 2 diabetes mellitus. Diabetes Res Clin Pract 109, 299-305. 80. Toro P, Schönknecht P, Schröder J (2009) Type II diabetes in mild cognitive impairment and Alzheimer's disease: results from a prospective population-based study 
in Germany. J Alzheimers Dis 16, 687-691.

81. Zhou Y, Fang R, Liu LH, Chen SD, Tang HD (2015) Clinical Characteristics for the Relationship between Type-2 Diabetes Mellitus and Cognitive Impairment: A CrossSectional Study. Aging Dis 6, 236-244.

82. Leibson CL, Rocca WA, Hanson VA, Cha R, Kokmen E, O'Brien PC, Palumbo PJ (1997) Risk of dementia among persons with diabetes mellitus: a population-based cohort study. Am J Epidemiol 145, 301-308.

83. Cheng D, Noble J, Tang MX, Schupf N, Mayeux R, Luchsinger JA (2011) Type 2 diabetes and late-onset Alzheimer's disease. Dement Geriatr Cogn Disord 31, 424-430. 84. Malek-Ahmadi M, Beach T, Obradov A, Sue L, Belden C, Davis K, Walker DG, Lue L, Adem A, Sabbagh MN (2013) Increased Alzheimer's disease neuropathology is associated with type 2 diabetes and ApoE ع.4 carrier status. Curr Alzheimer Res 10, $654-659$.

85. Janson J, Laedtke T, Parisi JE, O'Brien P, Petersen RC, Butler PC (2004) Increased risk of type 2 diabetes in Alzheimer disease. Diabetes 53, 474-481. 86. Roberts RO, Knopman DS, Cha RH, Mielke MM, Pankratz VS, Boeve BF, Kantarci K, Geda YE, Jack CR Jr, Petersen RC, Lowe VJ (2014) Diabetes and elevated hemoglobin A1c levels are associated with brain hypometabolism but not amyloid accumulation. J Nucl Med 55, 759-764.

87. Heitner J, Dickson D (1997) Diabetics do not have increased Alzheimer-type pathology compared with age-matched control subjects. A retrospective postmortem immunocytochemical and histofluorescent study. Neurology 49, 1306-1311. 88. Tariot PN, Ogden MA, Cox C, Williams TF (1999) Diabetes and dementia in long- 
term care. J Am Geriatr Soc 47,423-429.

89. Beeri MS, Silverman JM, Davis KL, Marin D, Grossman HZ, Schmeidler J, Purohit DP, Perl DP, Davidson M, Mohs RC, Haroutunian V (2005) Type 2 diabetes is negatively associated with Alzheimer's disease neuropathology. J Gerontol A Biol Sci Med Sci 60, 471-475.

90. Domínguez RO, Marschoff ER, González SE, Repetto MG, Serra JA (2012) Type 2 diabetes and/or its treatment leads to less cognitive impairment in Alzheimer's disease patients. Diabetes Res Clin Pract 98, 68-74.

91. Plastino M, Fava A, Pirritano D, Cotronei P, Sacco N, Sperlì T, Spanò A, Gallo D, Mungari P, Consoli D, Bosco D (2010) Effects of insulinic therapy on cognitive impairment in patients with Alzheimer disease and diabetes mellitus type-2. J Neurol Sci 288, 112-116.

92. Chen JM, Chang CW, Chang TH, Hsu CC, Horng JT, Sheu WH (2014) Effects of statins on incident dementia in patients with type $2 \mathrm{DM}$ : a population-based retrospective cohort study in Taiwan. PLoS One 9, e88434.

93. Rönnemaa E, Zethelius B, Sundelöf J, Sundström J, Degerman-Gunnarsson M, Berne C, Lannfelt L, Kilander L (2008) Impaired insulin secretion increases the risk of Alzheimer disease. Neurology 71, 1065-1071.

94. Baker LD, Cross DJ, Minoshima S, Belongia D, Watson GS, Craft S (2011) Insulin resistance and Alzheimer-like reductions in regional cerebral glucose metabolism for cognitively normal adults with prediabetes or early type 2 diabetes. Arch Neurol 68, 5157.

95. Craft S (2007) Insulin resistance and Alzheimer's disease pathogenesis: potential 
mechanisms and implications for treatment. Curr Alzheimer Res 4, 147-152.

96. Liu Y, Liu F, Grundke-lqbal I, Iqbal K, Gong CX (2011) Deficient brain insulin signalling pathway in Alzheimer's disease and diabetes. J Pathol 225, 54-62.

97. Liu Y, Liu F, Grundke-Iqbal I, Iqbal K, Gong CX (2009) Brain glucose transporters, O-GIcNAcylation and phosphorylation of tau in diabetes and Alzheimer's disease. J Neurochem 111, 242-249.

98. Kim I, Lee J, Hong HJ, Jung ES, Ku YH, Jeong IK, Cho YM, So I, Park KS, MookJung I (2010) A relationship between Alzheimer's disease and type 2 diabetes mellitus through the measurement of serum amyloid-beta autoantibodies. J Alzheimers Dis 19, $1371-1376$. 


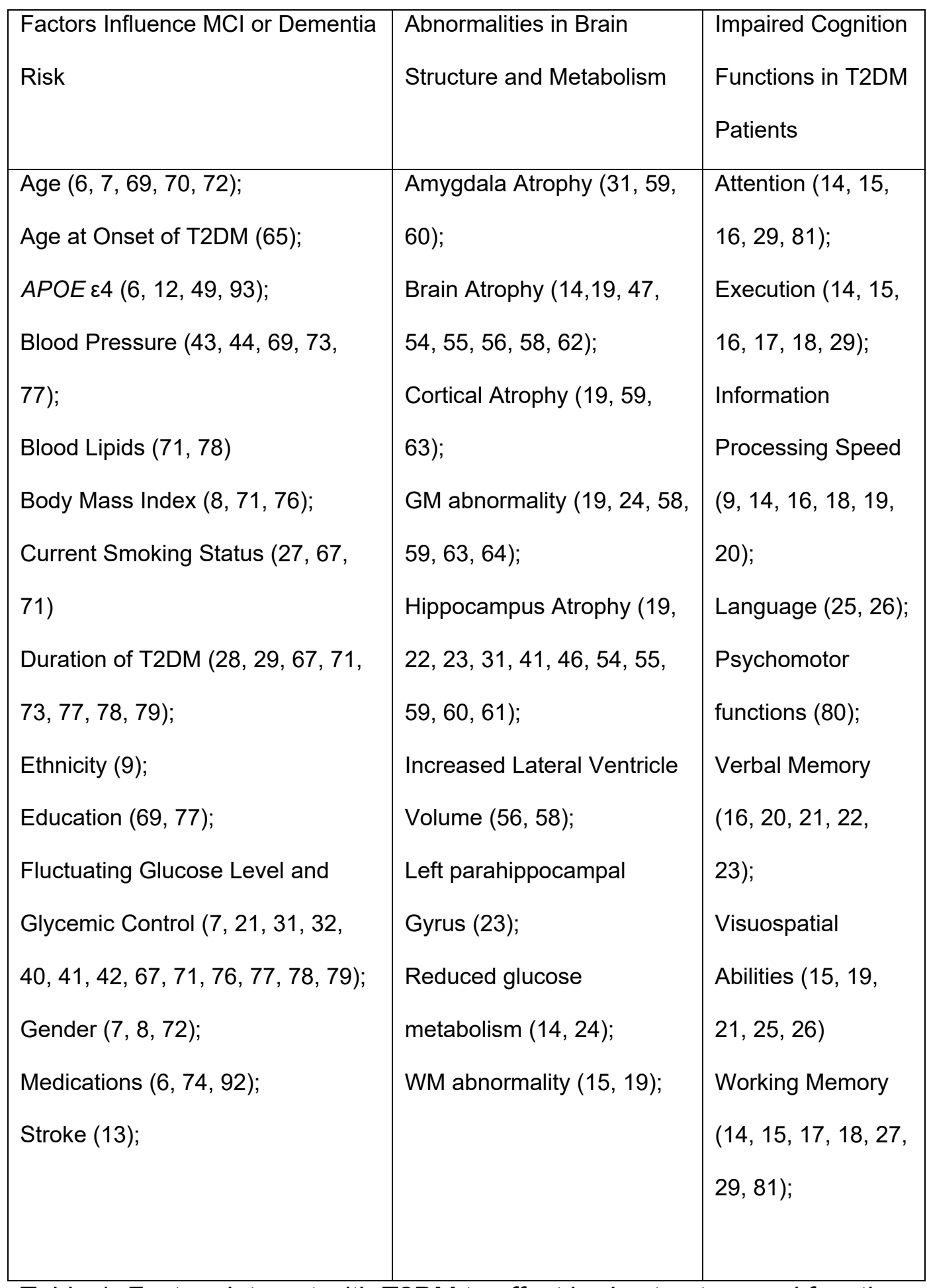

Table 1. Factors interact with T2DM to affect brain structure and functions of metabolism and cognition. APOE $\varepsilon 4$ : apolipoprotein $\mathrm{E} \varepsilon 4$; T2DM: type 2 diabetes mellitus; GM: gray matter; WM: white matter 


\begin{tabular}{|l|l|l|}
\hline Pathological & T2DM Related & T2DM related AD \\
Mechanisms for T2DM & VaD & Pathogenesis \\
Related Dementia & Pathogenesis & \\
\hline Glycation (33, 36, 37, & Cerebrovascular & Impaired glucose \\
$38) ;$ & Events $(3,13) ;$ & metabolism $(85,86,94) ;$ \\
Glycoxidation (34); & & Insulin Resistance $(60,93$, \\
Inflammation (36, 95) & & $94,95) ;$ \\
Vascular changes (16, & & Increased Tau \\
$45,46,47$ & & phosphorylation $(63,96,97)$ \\
& & \\
\hline
\end{tabular}

Table 2. Pathological mechanisms for T2DM related Dementia, $A D$ and $\mathrm{VaD}$. MCl: mild cognitive impairment; T2DM: type 2 diabetes mellitus; AD: Alzheimer's disease; APOE $\varepsilon 4:$ apolipoprotein E ع4; VaD: Vascular dementia 


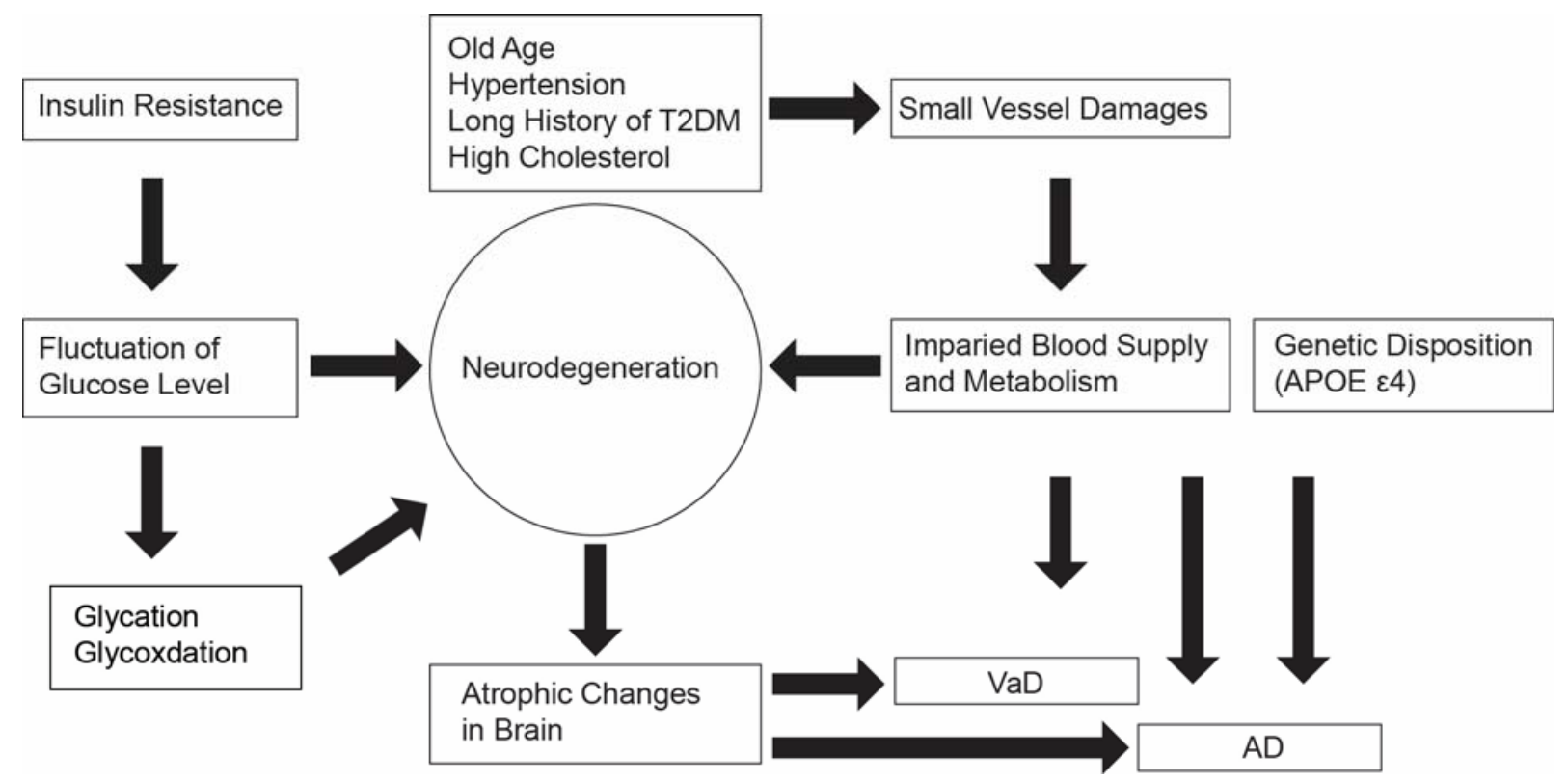

Figure 1. The possible pathological mechanisms for T2DM related dementia. AD:

Alzheimer's disease; APOE: apolipoprotein E; VaD: Vascular dementia. 